\title{
EVALUATION OF ORAL HYGIENE AND DIETARY STATUS AMONG EDENTULOUS, DENTATE AND DENTURE WEARERS IN THE ELDERLY
}

\author{
Syed Hamid Habib ${ }^{\prime \otimes}$, Afshan Gul', Muhammad Omar Malik', \\ Syed Rashid Habib ${ }^{2}$, Muhammad Akbar Khalil ${ }^{3}$
}

\begin{abstract}
OBJECTIVE: To evaluate the role of dentition and dentures on diet, body mass index and oral health among elderly population.

METHODS: This cross-sectional study included sixty elderly participants within age range of $60-75$ years. The participants were divided into three groups; Dentate, Edentulous and Complete-Denture wearers. Dietary data was obtained using the 24-hours dietary recall questionnaire and analyzed using Windiet ${ }^{\circledR}-2005$ software. Oral health status was assessed using the General Oral Health Assessment Index scale (GOHAl). Anthropometric measurements including lean body mass (LBM), body water and fat content were recorded with body composition analyzer. ANOVA with Tukey post-hoc analysis was done for comparison of results among groups.
\end{abstract}

RESULTS: Levels of various parameters showed vitamin $B_{12}(0.66 \pm 1.47 \mu \mathrm{g}$ vs $0.43 \pm 0.77 \mu \mathrm{g}, \mathrm{p}=0.04$ ) for complete-denture wearers vs edentulous; carotene $(615.8 \pm 58 \mu \mathrm{g}$ vs $257.0 \pm 228 \mu \mathrm{g}, \mathrm{p}=0.03)$ for dentate vs complete-denture and dietary fibers $(17.0 \pm 7.24 \mathrm{gm}$ vs $10.7 \pm 6.3 \mathrm{gm}, \mathrm{p}=0.0 \mathrm{I})$ for dentate vs edentulous respectively. LBM was $52.7 \pm 8.8 \mathrm{~kg}$ vs $42.2 \pm 6.5 \mathrm{~kg}(\mathrm{p}<0.00 \mathrm{I})$ in dentate vs complete-dentures and $52.5 \pm 8.8 \mathrm{~kg}$ vs $47.1 \pm 6.3 \mathrm{~kg}(\mathrm{p}=0.04)$ in dentate vs edentulous subjects, respectively. Mean caloric intake was $1750.9 \pm 132.9 \mathrm{KCal}$ vs $1649.1 \pm \mid 25.1 \mathrm{KCal}(\mathrm{p}=0.02)$ in dentate vs complete-dentures. Mean GOHAI was $33.3 \pm 1.2,31.8 \pm 2.6,26.5 \pm 2.6(p<0.00 I)$ in dentate, complete-dentures users \& edentulous subjects, respectively. Differences in rest of the parameters were non-significant.

CONCLUSION: The use of complete-dentures significantly improves oral health status. However, it does not improve the caloric intake and anthropometric measures compared to edentulous subjects. These parameters are not influenced by provision of complete-dentures; rather these are dependent on the duration of edentulousness.

KEY WORDS: Oral Health (MeSH); Aged (MeSH); Mouth, Edentulous (MeSH); Dentures, Complete (MeSH); Dentate, Edentulous (MeSH); Diet (MeSH); Energy Intake (MeSH); Body Mass Index (MeSH).

THIS ARTICLE MAY BE CITED AS: Habib SH, Gul A, Malik MO, Habib SR, Khalil MA. Evaluation of oral hygiene and dietary status among edentulous, dentate and denture wearers in the elderly. Khyber Med Univ J 2020; I2(3): 177-82. DOI: 10.35845/kmuj.2020.20I95.

\section{INTRODUCTION}

$M$ alnutrition is associated with a deterioration in functional status, weakened muscle activity and immunity, reduced bone mass and cognitive function, anemia, delayed wound repair and recovery from disease, longer hospital stays and readmission rate (25\%) of malnourished older adults.' The deficiency of essential vitamins is one of the major cause of malnutrition in aged population. $^{2}$

The degree of dental impairment, which causes chewing difficulty results in a change in selection of the type and
I. Department of Physiology, Institute of Basic Medical Sciences, Khyber Medical University, Peshawar, Pakistan.

2. Department of Prosthetic Dental Sciences, College of Dentistry, King Saud University, Riyadh, Kingdom of Saudi Arabia.

3. Department of Prosthodontics, Khyber College of Dentistry, Peshawar, Pakistan. Email凶: dr.hamidhabib@gmail.com Contact \# : +92-333-5247457

Date Submitted: March 27, 2020 Date Revised: $\quad$ August 26, 2020 Date Accepted: August 27, 2020

variety of food. This adversely effects the overall health of the elderly people and is a leading cause of malnutrition in them. ${ }^{3}$ The loss of natural teeth causes reduced chewing efficiency even after replacement with complete dentures, requiring more chewing strokes and longer time to swallow food than individual with natural teeth. ${ }^{4}$ Therefore, these elderly edentulous individuals avoid hard and coarse foods such as fruits, vegetables and meat, which are the major sources of vitamins, minerals, proteins and fiber, as these foods are difficult to chew with complete denture. This results in poor overall general health and quality of life of these individuals. ${ }^{5}$

Oral health is a fundamental part of the general health. Oral health related quality of life, ${ }^{6,7}$ shows how the oral condition can disturb one's capability to function. Geriatric Oral Health Assessment Index (GOHAl) is one of the tools used to assess oral health status in elderly patients. Individuals having more number of teeth have better GOHAl scores than those with no or fewer teeth. ${ }^{8}$

The amount of caloric intake, quality of food and dental hygiene can affect body mass index (BMI) and micronutrient status. It has been shown that the individuals having more than five pairs of 
TABLE I: COMPARISON OF DEMOGRAPHIC, BODY COMPOSITION PARAMETERS AND ORAL HEALTH STATUS IN THREE GROUPS

\begin{tabular}{|c|c|c|c|c|c|c|}
\hline \multirow{2}{*}{ Variable } & \multirow{2}{*}{ Dentate (D) } & \multirow{2}{*}{ Edentulous (E) } & \multirow{2}{*}{$\begin{array}{l}\text { Complete Denture } \\
\text { (CD) Wearer }\end{array}$} & \multicolumn{3}{|c|}{ P for comparison } \\
\hline & & & & D vs CD & D vs $E$ & CD vs $E$ \\
\hline Age (years) & $64.95 \pm 4.49$ & $64.86 \pm 5.23$ & $65.70 \pm 4.13$ & 0.86 & 0.99 & 0.83 \\
\hline Duration of Edentulousness (years) & $0 \pm 0$ & $3.35 \pm 5.18$ & $7.35 \pm 5.63$ & 0.002 & 0.55 & 0.03 \\
\hline Height $(\mathrm{cm})$ & $164.8 \pm 10.05$ & $162.19 \pm 6.69$ & $155.8 \pm 7.08$ & 0.002 & 0.55 & 0.03 \\
\hline Weight (kg) & $69.10 \pm 13.65$ & $60.70 \pm 10.46$ & $59.02 \pm 9.64$ & 0.01 & 0.055 & 0.88 \\
\hline $\mathrm{BMI}\left(\mathrm{kg} / \mathrm{m}^{2}\right)$ & $25.54 \pm 5.16$ & $23.12 \pm 4.15$ & $24.30 \pm 3.84$ & 0.64 & 0.19 & 0.67 \\
\hline Body Fat (\%) & $22.55 \pm 7.71$ & $20.57 \pm 10.49$ & $26.85 \pm 11.27$ & 0.36 & 0.80 & 0.11 \\
\hline Body Water (\%) & $52.05 \pm 5.21$ & $53.86 \pm 7.23$ & $49.4 \pm 7.63$ & 0.43 & 0.67 & 0.09 \\
\hline Lean Body Mass (kg) & $52.75 \pm 8.80$ & $47.10 \pm 6.36$ & $42.25 \pm 6.5 I$ & $<0.001$ & 0.04 & 0.09 \\
\hline Lean Mass (\%) & $76.33 \pm 7.8$ & $77.59 \pm 7.5$ & $71.59 \pm 7.13$ & 0.02 & 0.07 & 0.02 \\
\hline Fat Mass (kg) & $16.37 \pm 7.37$ & $13.59 \pm 8.22$ & $16.69 \pm 8.50$ & 0.99 & 0.51 & 0.43 \\
\hline $\mathrm{KCAL}$ & $1750.90 \pm 132.98$ & $1723.10 \pm 107.3$ & $1649.05 \pm 12.07$ & 0.02 & 0.74 & 0.13 \\
\hline GOHAI* & $33.28(32.6-33.9)$ & $26.46(25.1-27.8)$ & $31.79(30.5-33.1)$ & 0.22 & $<0.001$ & $<0.001$ \\
\hline
\end{tabular}

TABLE II: COMPARISON OF DIETARY MACRONUTRIENTS AMONG THE THREE GROUPS CALCULATED THROUGH WINDIET® SOFTWARE

\begin{tabular}{|c|c|c|c|c|c|c|}
\hline \multirow{2}{*}{ Variable } & \multirow{2}{*}{ Dentate (D) } & \multirow{2}{*}{ Edentulous (E) } & \multirow{2}{*}{$\begin{array}{l}\text { Complete Denture } \\
\text { (CD) Wearer }\end{array}$} & \multicolumn{3}{|c|}{ P for comparison } \\
\hline & & & & D vs $C D$ & D vs $E$ & $C D$ vs $E$ \\
\hline Fat (gm) & $35.78 \pm 23.82$ & $31.75 \pm 17.09$ & $37.86 \pm 27.54$ & 0.95 & 0.84 & 0.67 \\
\hline Protein $(\mathrm{gm})$ & $33.31 \pm 19.38$ & $28.47 \pm 15.16$ & $36.63 \pm 25.03$ & 0.86 & 0.72 & 0.40 \\
\hline Carbohydrate (gm) & $130.19 \pm 47.67$ & $120.04 \pm 58.50$ & $127.80 \pm 44.80$ & 0.98 & 0.79 & 0.87 \\
\hline Starch (gm) & $87.13 \pm 37.31$ & $72.37 \pm 38.98$ & $86.13 \pm 40.56$ & 0.99 & 0.45 & 0.49 \\
\hline NMEs (gm) & $26.73 \pm 19.48$ & $34.30 \pm 19.87$ & $28.70 \pm 13.78$ & 0.93 & 0.37 & 0.58 \\
\hline NSP (gm) & $8.38 \pm 4.62$ & $5.86 \pm 4.51$ & $6.82 \pm 4.74$ & 0.53 & 0.19 & 0.78 \\
\hline Water (gm) & $840.70 \pm 232.09$ & $1018.44 \pm 375.21$ & $857.92 \pm 327.91$ & 0.98 & 0.18 & 0.24 \\
\hline Dietary Fiber (gm) & $17.00 \pm 7.24$ & $10.73 \pm 6.39$ & $12.53 \pm 6.44$ & 0.09 & 0.01 & 0.66 \\
\hline SFA* $(\mathrm{gm})$ & $7.95(6.02-10.50)$ & $7.49(2.30-I .20)$ & $6.54(2.61-1.24)$ & 0.72 & 0.96 & 0.85 \\
\hline PUSFA* $(\mathrm{gm})$ & $6.02(3.89-9.34)$ & $3.67(2.34-5.75)$ & $4.93(2.72-8.96)$ & 0.82 & 0.31 & 0.65 \\
\hline Monos* $(\mathrm{gm})$ & $8.14(5.79-11.44)$ & $5.96(4.24-8.38)$ & $6.82(3.85-12.09)$ & 0.81 & 0.53 & 0.88 \\
\hline Cholesterol* (gm) & $52.30(32.97-82.96)$ & $42.75(24.83-73.6 I)$ & $44.34(22.37-87.87)$ & 0.90 & 0.85 & 0.99 \\
\hline
\end{tabular}

Values are Mean \pm SD. P=Tukey post hoc comparison between groups. ${ }^{*}=$ Values are log transformed for analysis, presented as geometric means (confidence interval). NME (Non milk extrinsic sugar), NSP (Non starch polysaccarides), SFA (Saturated Fatty acid), PUFSA (Poly unsaturated fatty acid), Monos (Mono-unsaturated fatty acid).

posterior occluding teeth have greater BMI than individuals with fewer teeth or using complete denture. In addition, the presence and absence of teeth and use of complete denture effects the BMI of elderly people.

As there is no local study to address the issue, we planned this study to assess the oral health status, BMI, diet and GOHAl among dentate, edentulous and complete denture wearer.

\section{METHODS}

This observational cross sectional study was conducted at Department of Prosthodontics, Khyber College of Dentistry, Peshawar and Department of
Physiology, Institute of Basic Medical Sciences, Khyber Medical University (KMU), Peshawar, Pakistan. The study was approved by the advanced studies and research board and ethical committee of KMU and conducted from June 2017 to December 2017. The sampling technique used was nonprobability random sampling technique.

A total of 60 elderly male and female participants within age range of $60-75$ years, divided into three groups of Dentate, Edentulous and Complete Denture wearers; each group having twenty participants were included in this study. For the dentate group, subjects having at least five or more posterior occluding pairs of teeth were selected. In the edentulous group, subjects who have been edentulous for a minimum period of six months were included. Subjects with uncontrolled diabetes, mental disorder, chronic periodontitis, damaged/worn dentition, active intraoral infection, muscular disorders, implant supported complete denture, removable partial denture, and long span fixed dental prosthesis were excluded from the study: after complete history, radiographic and clinical examination. For the complete denture wearers, the subjects recruited for the study were using their complete denture for a minimum period of two years.

All the willing potential participants 
were encouraged to participate in the study and potential participants were identified. Written informed consent was taken from all the participants. The questionnaires were provided to participants for recoding their responses. Although the printed questionnaire called for participants to express in written form, the study authors were ready to help them in understanding questions and recording their responses as well as recording the anthropometric measurements.

Dietary data of all the participants were obtained using the 24 hours dietary recall questionnaire and it was analyzed using the Windiet ${ }^{\circledR} 2005$ software. The Windiet software has a large number of food items and categorized meal time as breakfast, morning snack, lunch, evening snack and dinner.

Oral health status of the participants was assessed using GOHAl scale, ${ }^{10}$ which comprised of 12 questions. A sum up method (GOHAl-Add) was used to calculate the final score of the 12 $\mathrm{GOHAl}$ questions. The maximum score is 36 ( 12 = functional field; $15=$ psychosocial field; $9=$ pain or discomfort field).

Anthropometric parameters were measured by using the body composition analyser (CAMRY, model no-EF7 I IH) to calculate the lean body mass, body water and fat content etc. BMI was calculated from height in centimeters and weight in kilograms $\left(B M I=\mathrm{kg} / \mathrm{m}^{2}\right)$. Then through electrical impedance, the body fat percent, body water percent and the required kilocalories of each individual participant was recorded. From these values, lean body mass and fat mass in kilograms were calculated.

All the obtained data was statistically analyzed with SPSS ${ }^{\circledR}$ (Ver. 22.0, SPSS, Chicago, IL, USA). The data was normally distributed using Kolmogorov Smirinov tests and histograms were plotted except for GOHAl index which was logarithmically transformed for analysis. For comparing the three groups one-way ANOVA followed by Tukey's HSD Post Hoc test were used.

\section{RESULTS}

The lean body mass was significantly high in dentate compared to both edentulous $(p=0.004)$ and complete denture group $(p<0.00 I)$. The time duration of being edentulous was more in complete denture group as compared to dentate and edentulous (Table I). Furthermore, the GOHAl score showed that the oral health is better in dentate group compared to others $(p<0.00 \mathrm{I})$. However, complete denture group also showed improvement of oral health compared to edentulous $(p<0.00 \mathrm{I})$.

There was a statistically significant difference in the following parameters obtained after Windiet ${ }^{\circledR}$ analysis including vitamin $\mathrm{B}_{12}$ (complete denture vs edentulous; $0.66 \pm \mathrm{I} .47 \mu \mathrm{g} v \mathrm{~s} 0.43 \pm$ $0.77 \mu \mathrm{g}, \mathrm{p}=0.04$ ), Carotene (dentate vs complete denture: $615.8 \pm 58 \mu \mathrm{gvs}$ $257.0 \pm 228 \mu \mathrm{g}, \mathrm{p}=0.03)$ and dietary fibers (dentate vs edentulous;

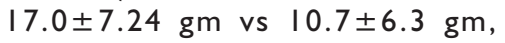
$\mathrm{p}=0.0 \mathrm{I})$. Among macronutrients only dietary fibers intake was significantly high in dentate $(17.0 \pm 7.24 \mathrm{gm}, \mathrm{p}=$ $0.0 \mathrm{l})$ compared to other two groups. The difference in the rest of the parameters was statistically nonsignificant (Table II and III). Mean intake

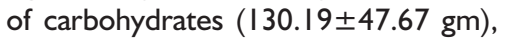
cholesterol [52.30 (32.97-82.96)], monosaturated fat $[8.14$ (5.79-II.44) $\mathrm{gm]}$ and non-starch polysaccharides $(8.38 \pm 4.62 \mathrm{gm})$ were high in dentate group showing increased intake of solid foods. Moreover, mean intake of fats $(37.86 \pm 27.54 \mathrm{gm})$ and proteins $(36.63 \pm 25.03 \mathrm{gm})$ were high in complete denture group as compared to dentate group suggesting better food intake and semi solid food. In edentulous group, more mean intake of water (1018.44 $\pm 375.21 \mathrm{gm})$ was observed suggesting fluid nature of most of the food intake (Table II).

TABLE III: COMPARISON OF DIETARY MICRONUTRIENTS (VITAMINS) AMONG THE THREE GROUPS CALCULATED THROUGH WINDIET ${ }^{\circledR}$ SOFTWARE

\begin{tabular}{|c|c|c|c|c|c|c|}
\hline \multirow{2}{*}{ Variable } & \multirow{2}{*}{ Dentate (D) } & \multirow{2}{*}{ Edentulous (E) } & \multirow{2}{*}{$\begin{array}{l}\text { Complete Denture } \\
\text { (CD) Wearer }\end{array}$} & \multicolumn{3}{|c|}{ P for comparison } \\
\hline & & & & D vs CD & D vs $E$ & CD vs $E$ \\
\hline Vitamin A $(\mu \mathrm{g})$ & $290.75 \pm 168.85$ & $275.14 \pm 194.79$ & $202.45 \pm 133.09$ & 0.22 & 0.95 & 0.35 \\
\hline Thiamine (mg) & $0.72 \pm 0.29$ & $0.52 \pm 0.28$ & $0.68 \pm 0.32$ & 0.89 & 0.09 & 0.22 \\
\hline Riboflavin (mg) & $0.49 \pm 0.23$ & $0.57 \pm 0.33$ & $0.58 \pm 0.31$ & 0.62 & 0.67 & 0.99 \\
\hline Niacin (mg) & $13.14 \pm 6.37$ & $11.48 \pm 6.42$ & $|4.5| \pm 8.65$ & 0.81 & 0.74 & 0.37 \\
\hline Vitamin $B_{6}(\mathrm{mg})$ & $0.78 \pm 0.39$ & $0.63 \pm 0.30$ & $0.73 \pm 0.45$ & 0.91 & 0.46 & 0.71 \\
\hline Folate $(\mu \mathrm{g})$ & $101.90 \pm 44.80$ & $78.19 \pm 44.29$ & $92.95 \pm 48.17$ & 0.81 & 0.22 & 0.55 \\
\hline Pantothenic acid $(\mu \mathrm{g})$ & $1.67 \pm 0.74$ & $1.68 \pm 0.90$ & $1.72 \pm 1.05$ & 0.98 & 0.99 & 0.98 \\
\hline Biotin $(\mu \mathrm{g})$ & $11.32 \pm 6.40$ & $11.09 \pm 5.97$ & $12.27 \pm 7.45$ & 0.89 & 0.99 & 0.83 \\
\hline Vitamin $\mathrm{B}_{12} *(\mu \mathrm{g})$ & $0.66(0.25-\mid .72)$ & $0.43(0.19-0.96)$ & $\mathrm{I} .77(0.8 \mathrm{I}-3.86)$ & 0.22 & 0.69 & 0.04 \\
\hline Vitamin C* (mg) & $20.45(11.48-36.42)$ & $12.53(6.63-23.69$ & $16.61(9.6-28.6)$ & 0.86 & 0.43 & 0.75 \\
\hline Vitamin D* $(\mu \mathrm{g})$ & $0.40(0.24-0.66)$ & $0.37(0.24-0.56)$ & $0.27(0.1-0.55)$ & 0.56 & 0.97 & 0.70 \\
\hline Vitamin $E^{*}(\mathrm{mg})$ & $2.82(1.79-4.45)$ & $2.30(\mathrm{I} .4 \mathrm{I}-3.76)$ & $1.97(1.3-2.97)$ & 0.48 & 0.78 & 0.86 \\
\hline Retinol* $(\mu \mathrm{g})$ & $66.4(45.9-96.1$ & $76.62(52.3-1 \mid 12.3)$ & $70.11(46.2-106.3)$ & 0.97 & 0.84 & 0.93 \\
\hline Carotene* $(\mu \mathrm{g})$ & $615.8(389.22-74.4)$ & $302.5(165.3-53.7)$ & $257(166.1-395.6)$ & 0.03 & 0.10 & 0.88 \\
\hline
\end{tabular}


When the dietary vitamins were compared significantly high levels were found for vitamin $B_{12}$ in complete denture wearers $[1.77(0.8 \mathrm{I}-3.86) \mu \mathrm{g}$, $\mathrm{p}=0.04]$ versus edentulous $[0.43(0.19$ $0.96) \mu g]$ group, and carotenes intake in dentate [6/5.8 (389.22-74.4) $\mathrm{Hg}$, $\mathrm{p}=0.03]$ versus complete denture wearers $[257.0($ I $66.1-395.6) \mu g]$. No statistical significance was found for the rest of the parameters (Table III). In complete denture group, more mean intake of riboflavin $(0.58 \pm 0.3 \mathrm{Img})$, niacin $(14.5 \mathrm{I} \pm 8.65 \mathrm{mg})$, and biotin ( $12.27 \pm 7.45 \mathrm{mg}$ ) was found. In edentulous group, mean intake of retinol [76.62 (52.3-I I2.3) $\mathrm{mg}]$ was more.

No statistical significance was found for mineral content of the diet among the three groups (Table IV). However, mean intake of most minerals were high in dentate group suggesting good quality of food. However, mean intake of calcium, phosphorous, and zinc were high among complete denture wearers when compared to edentulous.

Furthermore, the lean body mass was significantly high in dentate subjects compared to edentulous and complete denture (dentate vs complete denture) $(52.7 \pm 8.8 \mathrm{~kg}$ vs $42.2 \pm 6.5 \mathrm{~kg}$, $\mathrm{p}<0.00 \mathrm{I}$ ), (dentate vs edentulous) $(52.5 \pm 8.8 \mathrm{~kg}$ vs $47 . \mathrm{I} \pm 6.3 \mathrm{~kg}, \mathrm{p}=0.04)$. We also found the caloric intake was more in dentate patients compared to other groups (dentate vs complete denture) $(1750.9 \pm 132.9 \mathrm{KCal}$ vs 1649. I \pm I25. I KCal, $p=0.02$ ). Oral health status showed improvement in dentate and complete denture compared to edentulous subjects respectively $(33.3 \pm 1.2,31.7 \pm 2.6$, $26.5 \pm 2.6, p<0.00 \mathrm{I})$. Difference in rest of the parameters were non-significant.

\section{DISCUSSION}

Oral health plays an important role in the social, psychological and general wellbeing of an individual." For general and oral health of the elderly subjects, an appropriate and adequate nutrition is of great importance. It is proven in the research studies that poor oral function due to impaired dental status can cause chewing difficulty, dietary limitations and thus resulting in impaired nutritional status of these elderly. Masticatory efficiency is affected by the presence of teeth, the number of functional teeth, and the use of prostheses, which all influences the type and quality of food. ${ }^{12,13}$ The presence of five or more pairs of posterior teeth help the aged individuals to select the type of food they can easily chew and digest. ${ }^{14,15}$ This finding is also observed in our study that dentate individuals were taking more solid food, rich in fibers and micronutrients. ${ }^{14}$ Furthermore, the decrease in the solid food is seen in patients having no pairs of teeth, these are in accordance with the previous studies. ${ }^{9,16}$ The edentulous people prefer to use semi-solid and fluid food, which are low in essential nutrients. ${ }^{3,17}$ The preference is due to ease in chewing, swallowing, preparation, and affordability. ${ }^{18}$

Conventional complete denture is one of the most commonly used treatment modality for edentulous patients. However, with the use of complete denture, many problems such as pain, swelling, difficulty in speech/biting and chewing hard foods, can lead to denture stomatitis are reported. ${ }^{19,20}$ As a result, the edentulous patients with complete denture try to modify either their type of food or cooking methods. ${ }^{21}$ These issues can be addressed by use of implant supported dentures in place of conventional complete dentures. ${ }^{22}$ The advantage of implant supported dentures includes better support, stability and retention and better performance. However, dental implants are technique sensitive, surgical intervention is required and are costly. ${ }^{23}$ A low level of awareness about dental implants also exists and therefore, conventional complete denture are the treatment of choice for majority of the patients living in the under developed countries. ${ }^{24}$

In a study by Sahyoun NR, et al., BMI was found to increase with the decrease in number of teeth, due to decrease masticatory forces and more caloric food consumption. ' However, increase in BMI after denture use among edentulous people was observed. ${ }^{25}$ In another study by Hossain $M$, et al., the differences of the BMI values were found to be statistically significant $(p<0.05)$ both at 3 months and 6 months follow up compared to the base line value. ${ }^{26}$ No significant difference in BMI was observed in our study population. This might be because of the selection of participants in a specific age range or specific age limits.

Oral health related quality of life is good predictor of general wellbeing of an individual in a community. A number of methods have been used to measure oral health related quality of life, GOHAI being one of them. ${ }^{27} \mathrm{GOHAl}$ is very easy, simple and reliable tool to assess oral health status of elderly population as perceived by the individual..$^{10}$ It was observed that oral hygiene and quality of life improved with the use of complete denture when compared with the edentulous group. These findings are supported by many previous research that use of complete denture causes improvement in oral health and social wellbeing of an individual. ${ }^{28,29}$

In contrast, improvement in functionality, mastication and selfconfidence was observed by Shigli K, et al.,' In our study oral health showed significant improvement but the dietary intake was not significantly improved with denture use when compared to those with teeth. This might be due to the fact that even with the use of complete denture, patients face difficulty in using artificial teeth due to factors as previously described.

The health status was more related to the duration of individual becoming edentulous as was observed in this study. The individual using complete denture were edentulous for significantly high time $(7.35 \pm 5.63)$ compared to edentulous ( $3.35 \pm 5.18)$. The longer the duration of individual without teeth the worse is the health condition. This was unexpected as with the use of denture improvement was expected as previously seen in the studies. $^{7,30}$

The results of the current study must be applied cautiously, as the sample size in this study is small and food intake was recorded only for one day through 24hour dietary recall. The results would be more reliable with the use of 3 and 7 days' record. ${ }^{16,31}$ However, the 
advantage of 24-hour dietary record is its simplicity, quick use and feasibility to mentally recall for the elderly after one day. The disadvantage being it does not give long term information about food intake. ${ }^{32}$ While in 3 and 7 days' recall methods, there is compliance and recall bias can be an issue. To overcome these problems, diet diary can be provided for dental analysis of food intake. ${ }^{33}$

\section{CONCLUSION}

The use of complete denture in edentulous patients significantly improves their oral health status. However, it does not improve the caloric intake and anthropometric measures in these edentulous patients. These parameters are not dependent on the provision of complete dentures but rather are dependent on the duration of edentulousness.

\section{ACKNOWLEDGEMENTS}

We thank Mr. Safi-ur-Rehman for providing technical assistance in laboratory equipment. We are very grateful to our study participants for their cooperation.

\section{REFERENCES}

I. Thomas DR, Zdrowski CD, Wilson M-M, Conright KC, Lewis C, Tariq $\mathrm{S}$, et al. Malnutrition in subacute care. Am J Clin Nutr 2002;75(2): 308-I3. DOI: 10.1093/ajcn/75.2. 308.

2. Montgomery SC, Streit SM, Beebe ML, Maxwell IV PJ. Micronutrient needs of the elderly. Nutr Clin Pract 20I4;29(4):435-44. DOI: 10. | |77/08845336|4537684.

3. Nowjack-Raymer R, Sheiham A. Association of edentulism and diet and nutrition in US adults. J Dent Res 2003;82(2):123-6. DOI: 10. I I77/I54405910308200209.

4. Helkimo E, Carlsson GE, Helkimo $M$. Chewing efficiency and state of dentition: a methodologic study. Acta Odontologica Scandinavica 1978;36(I):33-4I. DOI: 10.3109/ 00016357809026364.

5. Yoshida M, Suzuki R, Kikutani T. Nutrition and oral status in elderly people. Jap Dent Sci Rev 2014; 50(I):9-14.

6. Dorri M, Sheiham A, Tsakos G. Validation of a Persian version of the OIDP index. BMC Oral Health 2007;7(1):2.

7. Shigli K, Hebbal M. Assessment of changes in oral health-related quality of life among patients with complete denture before and I month post-insertion using Geriatric Oral Health Assessment Index. Gerodontology 2010;27(3): |67-73. DOI: |0. | | | |/j. |74|-2358. 2009.00323.

8. Gerritsen AE, Allen PF, Witter DJ, Bronkhorst EM, Creugers NH. Tooth loss and oral health-related quality of life: a systematic review and meta-analysis. Health Qual Life Outcomes 2010;8(I): 126. DOI: 10. I I86/I477-7525-8-I 26.

9. Sahyoun NR, Lin C-L, Krall E. Nutritional status of the older adult is associated with dentition status. J Am Diet Assoc 2003;103(I):61-6. DOI: 10.1053/jada.2003.50003.

10. Atchison KA, Dolan TA. Development of the geriatric oral health assessment index. J Dent Educ 1990;54(I I):680-7.

II. Gil-Montoya JA, de Mello ALF, Barrios R, Gonzalez-Moles MA, Bravo M. Oral health in the elderly patient and its impact on general well-being: a nonsystematic review. Clin Inter Aging 20 I 5; 10:46I.

12. Samnieng P, Ueno M, Shinada K, Zaitsu T, Wright FAC, Kawaguchi Y. Oral health status and chewing ability is related to mini-nutritional assessment results in an older adult population in Thailand. J Nutr in Geronto Geriatr 201 I;30(3):291304. DOI: I0.2I47/CIA.S54630.

13. Banerjee R, Chahande J, Banerjee S, Radke U. Evaluation of relationship between nutritional status and oral health related quality of life in complete denture wearers. Indian J Dent Res 2018;29(5):562-7. DOI: 10.4103/ijdr.IJDR_285_17.

14. Nowjack-Raymer R, Sheiham A. Numbers of natural teeth, diet, and nutritional status in US adults. J Dent
Res 2007;86(I2): I I7I-5. DOI: 10. I I 77//5440591070860I 206.

15. Savoca MR, Arcury TA, Leng X, Chen H, Bell RA, Anderson AM, et al. Severe tooth loss in older adults as a key indicator of compromised dietary quality. Public Health Nutr 20I0; I3(4):466-74, DOI: 10.1017/ SI36898000999I 236 .

16. Sheiham A, Steele J, Marcenes W, Lowe C, Finch S, Bates C, et al. The relationship among dental status, nutrient intake, and nutritional status in older people. J Dent Res 200I; 80(2):408-I3. DOI: 10.1 I77/ 00220345010800020201 .

17. Lee JS, Weyant RJ, Corby P, Kritchevsky SB, Harris TB, Rooks R, et al. Edentulism and nutritional status in a biracial sample of wellfunctioning, community-dwelling elderly: the health, aging, and body composition study. Am J Clin Nutr 2004;79(2):295-302. DOI: 10.1093/ajcn/79.2.295.

18. Emami E, de Souza RF, Kabawat M, Feine JS. The impact of edentulism on oral and general health. Int J Dent 20I3;20I3:498305. DOI;10.II55/ $2013 / 498305$.

19. Jainkittivong A, Aneksuk V, Langlais RP. Oral mucosal lesions in denture wearers. Gerodontology 2010;27(I): 26-32. DOI: 10.1III/ j. I 74I-2358. 2009.00289.x.

20. Čelebić A, Knezović-Zlatarić D. A comparison of patient's satisfaction between complete and partial removable denture wearers. J Dent 2003;3I(7):445-5I. DOI: 10.1016/ s0300-57/2(03)00094-0.

21. Budtz-Jørgensen E, Chung JP, Rapin $\mathrm{CH}$. Nutrition and oral health. Best Pract Res Clin Gastroenterol 200I;I5(6):885-96. DOI: 10.1053/ bega. 2001.0247

22. Heydecke G, Locker D, Awad MA, Lund JP, Feine JS. Oral and general health related quality of life with conventional and implant dentures. Community Dent Oral Epidemiol 2003;3I(3):|6I-8. DOI: 10.1034/ j. 1600-0528.2003.00029.x.

23. Doundoulakis JH, Eckert SE, Lindquist CC, Jeffcoat MK. The 
implant-supported overdenture as an alternative to the complete mandibular denture. J Am Dent Assoc 2003;134(I I): I455-8. DOI: 10. 14219/jada.archive.2003.0073.

24. Gbadebo OS, Lawal FB, Sulaiman AO, Ajayi DM. Dental implant as an option for tooth replacement: The awareness of patients at a tertiary hospital in a developing country. Contemp Clin Dent 20 I 4;5(3):3026. DOI: $10.4103 / 0976-237 \mathrm{X}$. I379|4.

25. Madhuri S, Hegde SS, Ravi S, Deepti A, Simpy M. Comparison of chewing ability, oral health related quality of life and nutritional status before and after insertion of complete denture amongst edentulous patients in a Dental College of Pune. Ethiop J Health Sci 20I4;24(3):253-60. DOI: 10.43/4/ ejhs.v24i3.9.

26. Hossain $M$, Uddoula $M$, Mahmuduzzaman M, Rahman $M$. Evaluation of Body Mass Index Before and After Prosthetic
Rehabilitation with Complete Denture Therapy. Mymensingh MedJ 20I6;25(4):698-702.

27. Klotz A-I, Hassel AJ, Schröder J, Rammelsberg P, Zenthöfer A. Oral health-related quality of life and prosthetic status of nursing home residents with or without dementia. Clin Inter Aging 2017;12:659-65. DOI: 10.2147/CIA.SI25I 28.

28. Veyrune J, Tubert-Jeannin S, Dutheil C, Riordan P. Impact of new prostheses on the oral health related quality of life of edentulous patients. Gerodontology 2005;22(I):3-9, DOI: 10.1 I I / j. |74|-2358.2004.00048.x.

29. Dable RA, Nazirkar GS, Singh SB, Wasnik PB. Assessment of oral health related quality of life among completely edentulous patients in Western India by using GOHAI. J Clin Diag Res 2013;7(9):2063-7. DOI: $10.7860 / J C D R / 2013 / 6377$. 3406.

30. Ellis JS, Pelekis ND, Thomason JM.
Conventional rehabilitation of edentulous patients: the impact on oral health related quality of life and patient satisfaction. J Prosthodont 2007;16(I):37-42. DOI: 10.1 III/ j.I532-849X.2006. $00152 . x$.

31. Volkert D, Kreuel K, Heseker H, Stehle P. Energy and nutrient intake of young-old, old-old and very-old elderly in Germany. Eur J Clin Nutr 2004;58(8): I 190-200. DOI: I0.1038/sj.ejcn. 1601950 .

32. Thompson FE, Subar AF. Dietary assessment methodology. In: Coulston AM, Boushey CJ, Ferruzzi MG, Delahanty LM (eds) Nutrition in the Prevention and Treatment of Disease. Elsevier Academic Press; 2017. pp 5-48. DOI: 10.1016/B9780-। 2-802928-2.0000।-I.

33. Shim J-S, Oh K, Kim HC. Dietary assessment methods in epidemiologic studies. Epidemiol Health 20I4;36:e20I4009. DOI: 10.4I78/epih/e2014009.

\section{AUTHORS' CONTRIBUTIONS}

Following authors have made substantial contributions to the manuscript as under:

SHH: Study design, analysis and interpretation of data, drafting the manuscript, final approval of the version to be published

AG: Acquisition of data, drafting the manuscript, final approval of the version to be published

MOM: Analysis and interpretation of data, critical revision, final approval of the version to be published

SRH: Conception, drafting the manuscript, critical revision, final approval of the version to be published

MAK: Acquisition of data, critical revision, final approval of the version to be published

Authors agree to be accountable for all aspects of the work in ensuring that questions related to the accuracy or integrity of any part of the work are appropriately investigated and resolved.

CONFLICT OF INTEREST
Authors declared no conflict of interest
GRANT SUPPORT AND FINANCIAL DISCLOSURE
NIL

DATA SHARING STATEMENT
Data available on request due to
privacy / ethical restrictions

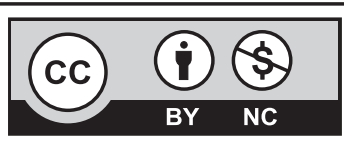

This is an Open Access article distributed under the terms of the Creative Commons Attribution-Non Commercial 2.0 Generic License.

\section{KMUJ web address: www.kmuj.kmu.edu.pk}

Email address: kmuj@kmu.edu.pk 